\title{
Mental health assessment of healthcare workers in the Emergency Department of a low middle-income country during COVID 19 pandemic
}

\section{Shahan Waheed}

Aga Khan University Hospital Karachi

Nirdosh Kumar ( $\square$ nirdosh.kumar@aku.edu )

Aga Khan University Hospital Karachi

\section{Bushra Qureshi}

Aga Khan University Hospital Karachi

Ahmed Rahim

Aga Khan University Hospital Karachi

\section{Research Article}

Keywords: Emergency Department, Depression, Anxiety, Healthcare workers, COVID 19

Posted Date: July 26th, 2021

DOI: https://doi.org/10.21203/rs.3.rs-741263/v1

License: (a) This work is licensed under a Creative Commons Attribution 4.0 International License. Read Full License 


\section{Abstract \\ Introduction:}

Emergency department healthcare workers of Pakistan during COVID 19 pandemic are facing an acute rise of mental illnesses. In the present study, the authors aim to assess the frequency of anxiety and depression among healthcare workers in the emergency department.

\section{Methods:}

A cross-sectional online survey was conducted in the emergency department between July to August 2020 at Aga Khan University Hospital Karachi, Pakistan. The Hospital Anxiety and Depression (HAD) scale was used for mental illness assessment among emergency physicians and nurses. Descriptive analysis of grading as per Likert scale is done through frequencies, means and standard deviations. Categorical variables were expressed as frequency (\%). Mann-Whitney $\mathrm{U}$ test was used to compare scores of various groups and sub-groups and Chisquare test was used to assess the association of depression and anxiety categories among the groups.

\section{Results:}

In the emergency department, 127 healthcare professionals (physicians and nurses) were included in this survey. Median depression score was 8 (IQR 6-10) with 21\% (27) fall under depression and $39 \%(50)$ to borderline depression. Median anxiety score was 9 (IQR 7-12) with 33\% (42) had abnormal, 38\% (48) had borderline anxiety. Healthcare workers working for $>45$ hours per week have odds of 3.62 [1.374-9.549] of developing depression compared to anxiety with a p-value of 0.009 . Similarly, nurses and medical officers develop depression with odds of 2.18 [1.016-4.686] p-value 0.045 and 5.18 [0.197-1.02] p-value 0.002, respectively.

\section{Conclusion:}

In our study, we determined that healthcare workers working in the Emergency Department during COVID-19 pandemic suffered high levels of anxiety and depression, which is a matter of concern. Therefore, comprehensive support and training of emergency department healthcare providers are paramount to promote physical and mental wellbeing specifically through adequate provision and training on the use of personal protective equipment, strict infection control practices, shorter shift length, and provision of mental health and support services.

\section{Introduction}

Anxiety and Depression are commonly reported mental illness disorders around the world[1]. The burden of mental illnesses is profound among healthcare workers and emergency departments in the current COVID 19 pandemic is sharing a major burden all over the world. A load of mental illness is plagued by variability in reported prevalence rates and lack of published data from low resource settings like Pakistan[2]. Previous 
studies from Pakistan does report an overall prevalence of anxiety and depression in the community to be $34 \%$ (range 29-66\% among women and 10-33\% for men)[1],[3]. The emergency department healthcare workers by their job are at increased risk of mental health problems[4]. The emergence of COVID 19 in Pakistan developed an unprecedented situation for emergency department healthcare workers who are at the frontline and making decisions under extreme pressures. The decisions made are influenced through factors like scant resources, the practice of justice and equity and keeping in deliberation ones physical and psychological needs responsibly.

The assessment of mental illness in the emergency department includes anxiety and depression, which are not routinely assessed. The studies report that developing countries have almost two-thirds of psychiatric patients in the world[5],[6]. The ongoing COVID 19 pandemic with its associated stress and the weak healthcare systems may worsen the psychological impact on the medical system's first line of defense. Mental illness issues during a pandemic are often overlooked by the healthcare professionals themselves putting them at risk of developing anxiety and depression and hence poor outcomes. The previously published studies have focused broadly on mental health issues and utilized different scales[5]. Our study is focused exclusively on the emergency department healthcare workers by utilizing the HAD scale which is a validated scale in our population[7].

In the present study, we, therefore, aim to determine the frequency of anxiety and depression among the healthcare workers working in the emergency departments during the COVID 19 pandemic in Pakistan. We also explore the personal, social, and environmental factors that were responsible for workplace anxiety and depression. The study is important from Pakistan, as it is the only study to date that have focused emergency department healthcare workers in COVID 19 pandemic. Moreover, the factors that are explored can later be intervened to either minimize or decommission the risk of mental health illness among healthcare workers in the emergency department.

\section{Methods}

A cross-sectional online hospital-based survey was conducted in the Emergency Department of Aga Khan University Hospital (AKUH) between July to August 2020. The emergency department is a 62 bedded facility located in Karachi,

Pakistan that receives 60,000 patients annually. The study participants were selected through consecutive sampling and include emergency department physicians and nurses involved in patient care during the COVID 19 pandemic. Participants with known psychiatric disorder or ailments related to stress like psoriasis and irritable bowel syndrome were excluded. The reason for excluding these two groups is that these disorders have the potential of causing mental illness and may not represent the true effect of COVID 19 on healthcare staff. Moreover, as we did not have previous baseline data of mental illness among emergency department healthcare staff, we aim to exclude all factors that may falsely estimate the current burden of mental health illness among the emergency health care workers. The study questionnaire was pre-tested and then circulated to the emergency department healthcare workers through email and WhatsApp Fig. 1.

the questionnaire consists of demographic variables like age, sex and components of Hospital Anxiety and Depression (HAD) scale. It contains seven questions for anxiety and seven questions for depression. The HAD 
scale was chosen because of its validation in previous studies in our population. It is one of the National Institute for Health and Care Excellence (NICE) recommended tools for the diagnosis of depression and anxiety among healthcare professionals. Anxiety was defined as a mental state characterized by a diffuse, unpleasant, vague sense of apprehension often accompanied by autonomic symptoms such as headache, palpitations, and restlessness. Depression was defined as a mental state characterized by a feeling of sadness, despair, loneliness, low self-esteem, and self-reproach persistent for 2 weeks. Additionally, data of associated factors like the number of duties per week, number of hours per week, availability of personal protective equipment (PPE), number of hours working with PPE per week were also collected. The cut-off scores for quantification were taken as previously tried and tested in the literature. The primary outcome was the frequency of anxiety

and depression among healthcare professionals in the emergency department. Each survey form was given a unique identification number to maintain confidentiality and no personal identifiers were noted. The study was reviewed by the institutional ethical review committee and was given exemption (ERC 2020-4771-10978).

\section{STATISTICAL ANALYSIS:}

The analysis was based on respondents who provided complete data. Descriptive statistics are presented as frequencies and percentages for categorical variables. Basic descriptive statistical analysis of grading as per Likert scale is done by calculating frequencies, mean, and standard deviations. Normality of the distribution of age (years), depression and anxiety score, were measured by applying Shapiro-Wilk test and p-value $<0.05$ is considered statistically significant. Median and interquartile range (IQR) were computed and Mann-Whitney $U$ test was used to compare scores by various groups and sub-groups of participants. Categorical variables were expressed as frequency (\%) and Chi-square test was applied to assess the association of depression and anxiety, by various groups and sub-groups of participants. The percentage of grading of all emergency healthcare workers was calculated by combining the frequency of each item in the questionnaire. The responses on the Likert scale were totaled for each item. The data was entered and analyzed using IBM SPSS statistical package for windows version 20 .

\section{Results}

A total of 127 participants were included in this survey with a response rate of $51 \%$. Hospital Anxiety and Depression Scale (HADS) for all two domains with Cronbach's alpha coefficient was 0.85 [95\% C.I: $0.808-$ 0.886], inter-rater reliability of depression score was 0.722 [95\% C.I 0.64-0.791] and anxiety 0.779 [95\% C.I: $0.713-0.833$ ]. The median depression score was 8 [IQR: 6-10] with $21 \%$ (27) fall under the abnormal depression category and $39 \%$ (50) with normal to borderline depression. The median anxiety score was 9 [IQR: 7-12] with 33\% (42) had abnormal and 29\% (37) normal and 38\% (48) with borderline anxiety. $35 \%$ (45) of them were Registered Nurse, $32 \%$ (40) medical officers and only $8 \%(10)$ were a consultant. Majority of participants were under the age of 30 years $63 \%$ (80) and almost 78\% (99) had working ED experience of fewer than five years. $70 \%$ (89) participant found spending more than 45 hours in the emergency department and directly or indirectly exposed to COVID-19 suspected and confirmed patients. Demographic profile, year of experience, and COVID-19 exposure of participants are presented in Table 1 below. 
Table 1

Demographic profile, year of experience, and COVID-19 exposure of the participants

\begin{tabular}{|c|c|}
\hline Characteristics & Total \\
\hline Total $(\mathrm{N})$ & 127 \\
\hline \multicolumn{2}{|l|}{ Median [IQR] } \\
\hline Depression score & 8 [IQR: 6-10] \\
\hline Anxiety Score & 9 [IQR: 7-12] \\
\hline \multicolumn{2}{|c|}{ Cronbach's alpha coefficient } \\
\hline Overall Reliability & 0.85 [95\% C.I: $0.808-0.886]$ \\
\hline Depression & 0.722 [95\% C.I 0.64-0.791] \\
\hline Anxiety & 0.779 [ 95\% C.I: 0.71-0.833]. \\
\hline \multicolumn{2}{|l|}{ Designation } \\
\hline Resident & $25 \%(32)$ \\
\hline Medical Officer & $32 \%(40)$ \\
\hline Registered Nurse & $35 \%(45)$ \\
\hline Consultant & $8 \%(10)$ \\
\hline \multicolumn{2}{|l|}{ Age Groups } \\
\hline$<=30$ Years & $63 \%(80)$ \\
\hline$>30$ Years & $37 \%(47)$ \\
\hline \multicolumn{2}{|c|}{ Years of experience working in the ED? } \\
\hline$<=5$ Years & $78 \%(99)$ \\
\hline$>5$ Years & $22 \%(28)$ \\
\hline \multicolumn{2}{|c|}{ How many hours do you spend working in the ED per week? } \\
\hline$<=45$ Hours & $30 \%(38)$ \\
\hline$>45$ Hours & $70 \%(89)$ \\
\hline \multicolumn{2}{|l|}{ Anxiety } \\
\hline Normal $(0-7)$ & $29 \%(37)$ \\
\hline Borderline (8-10) & $38 \%(48)$ \\
\hline Abnormal (11-21) & $33 \%(42)$ \\
\hline \multicolumn{2}{|l|}{ Depression } \\
\hline Normal (0-7) & $39 \%(50)$ \\
\hline
\end{tabular}




\begin{tabular}{|ll|}
\hline Characteristics & Total \\
\hline Borderline $(8-10)$ & $39 \%(50)$ \\
\hline Abnormal $(11-21)$ & $21 \%(27)$ \\
\hline Consent Scientific Purpose & \\
\hline Yes & $98.4 \%(125)$ \\
\hline No & $1.6 \%(2)$ \\
\hline
\end{tabular}

Similarly, categories of Anxiety and depression were found to be comparatively higher among participants who had an age group of fewer than 30 years $\left(p\right.$-value $\left.=0.007^{*}\right)$, and most of the registered nurse found significantly abnormal depression $\left(p\right.$-value $\left.=0.015^{\star}\right)$. Participants who have abnormal depression and anxiety were found to spend more hours in an emergency $\left(p\right.$-value $\left.=0.016^{*}\right)$. Depression and anxiety levels stratified by the COVID-19 status of the participant is presented in Table 2 below. 
Table 2

Depression, anxiety levels stratified by the COVID-19 status of the participant.

\begin{tabular}{|c|c|c|c|c|c|c|c|c|}
\hline & Anxiety & & & & Depressi & & & \\
\hline & Normal & Borderline & Abnormal & \multirow{2}{*}{$\begin{array}{l}P \text { - } \\
\text { value }\end{array}$} & Normal & Borderline & Abnormal & \multirow{2}{*}{$\begin{array}{l}\mathrm{P}- \\
\text { value }\end{array}$} \\
\hline $\mathrm{N}$ & 37 & 48 & 52 & & 50 & 50 & 27 & \\
\hline \multicolumn{9}{|l|}{ Age Groups } \\
\hline$<=30$ Years & $\begin{array}{l}14.2 \% \\
(18)\end{array}$ & $\begin{array}{l}21.3 \% \\
(27)\end{array}$ & $\begin{array}{l}26.8 \% \\
(34)\end{array}$ & \multirow[t]{2}{*}{$0.007 *$} & $\begin{array}{l}20.5 \% \\
(26)\end{array}$ & $26 \%(33)$ & $\begin{array}{l}15.7 \% \\
(20)\end{array}$ & \multirow[t]{2}{*}{0.126} \\
\hline > 30 Years & $\begin{array}{l}15 \% \\
(19)\end{array}$ & $\begin{array}{l}16.5 \% \\
(21)\end{array}$ & $6.3 \%(8)$ & & $\begin{array}{l}18.9 \% \\
(24)\end{array}$ & $\begin{array}{l}13.4 \% \\
(17)\end{array}$ & $5.5 \%(7)$ & \\
\hline \multicolumn{9}{|l|}{ Designation } \\
\hline Resident & $\begin{array}{l}3.9 \% \\
(5)\end{array}$ & $9.4 \%(12)$ & $\begin{array}{l}11.8 \% \\
(15)\end{array}$ & \multirow[t]{4}{*}{$0.015 *$} & $\begin{array}{l}6.3 \% \\
(8)\end{array}$ & $9.4 \%(12)$ & $9.4 \%(12)$ & \multirow[t]{4}{*}{$0.048 *$} \\
\hline $\begin{array}{l}\text { Medical } \\
\text { Officer }\end{array}$ & $\begin{array}{l}12.6 \% \\
(16)\end{array}$ & $15 \%(19)$ & $3.9 \%(5)$ & & $\begin{array}{l}15 \% \\
(19)\end{array}$ & $11 \%(14)$ & $5.5 \%(7)$ & \\
\hline $\begin{array}{l}\text { Registered } \\
\text { Nurse }\end{array}$ & $\begin{array}{l}10.2 \% \\
(13)\end{array}$ & $9.4 \%(12)$ & $\begin{array}{l}15.7 \% \\
(20)\end{array}$ & & $\begin{array}{l}15.7 \% \\
(20)\end{array}$ & $\begin{array}{l}13.4 \% \\
(17)\end{array}$ & $6.3 \%(8)$ & \\
\hline Consultant & $\begin{array}{l}2.4 \% \\
(3)\end{array}$ & $3.9 \%(5)$ & $1.6 \%(2)$ & & $\begin{array}{l}2.4 \% \\
(3)\end{array}$ & $5.5 \%(7)$ & $0 \%(0)$ & \\
\hline \multicolumn{9}{|l|}{$\begin{array}{l}\text { Hours } \\
\text { Spending } \\
\text { ED }\end{array}$} \\
\hline$<=45$ Hours & $\begin{array}{l}12.6 \% \\
(16)\end{array}$ & $\begin{array}{l}12.6 \% \\
(16)\end{array}$ & $4.7 \%(6)$ & \multirow[t]{2}{*}{$0.016 *$} & $\begin{array}{l}12.6 \% \\
(16)\end{array}$ & $\begin{array}{l}12.6 \% \\
(16)\end{array}$ & $4.7 \%(6)$ & \multirow[t]{2}{*}{0.616} \\
\hline$>45$ Hours & $\begin{array}{l}16.5 \% \\
(21)\end{array}$ & $\begin{array}{l}25.2 \% \\
(32)\end{array}$ & $\begin{array}{l}28.3 \% \\
(36)\end{array}$ & & $\begin{array}{l}26.8 \% \\
(34)\end{array}$ & $\begin{array}{l}26.8 \% \\
(34)\end{array}$ & $\begin{array}{l}16.5 \% \\
(21)\end{array}$ & \\
\hline \multicolumn{9}{|l|}{$\begin{array}{l}\text { Working } \\
\text { Experience } \\
\text { ED }\end{array}$} \\
\hline$<=5$ Years & $\begin{array}{l}21.3 \% \\
(27)\end{array}$ & $\begin{array}{l}28.3 \% \\
(36)\end{array}$ & $\begin{array}{l}28.3 \% \\
(36)\end{array}$ & \multirow[t]{2}{*}{0.325} & $\begin{array}{l}30.7 \% \\
(39)\end{array}$ & $\begin{array}{l}29.1 \% \\
(37)\end{array}$ & $\begin{array}{l}18.1 \% \\
(23)\end{array}$ & \multirow[t]{2}{*}{0.528} \\
\hline > 5 Years & $\begin{array}{l}7.9 \% \\
(10)\end{array}$ & $9.4 \%(12)$ & $4.7 \%(6)$ & & $\begin{array}{l}8.7 \% \\
(11)\end{array}$ & $\begin{array}{l}10.2 \% \\
(13)\end{array}$ & $3.1 \%(4)$ & \\
\hline
\end{tabular}

The Odds of participants screened positive for severe depression and anxiety with age, year of service in the emergency department, working hours in past 7 days, year of residency, nature of the job and personal protective equipment is worn for how many hours are presented in Table 3. 
Table 3

Odds of participants been screened positive for severe depression, anxiety, with demographic characteristics and pre-existing study characteristics.

\begin{tabular}{|c|c|c|c|c|}
\hline \multirow[t]{2}{*}{ Study Characteristics } & \multicolumn{2}{|l|}{ Depression } & \multicolumn{2}{|l|}{ Anxiety } \\
\hline & OR [95\% Cl] & p-value & OR [95\% Cl] & p-value \\
\hline Age groups & 3.78 [1.567-9.109 ] & $0.003^{*}$ & $0.63[0.308-1.267]$ & 0.192 \\
\hline Working Experience & $0.48[0.177-1.286]$ & 0.144 & $0.55[0.173-1.751]$ & 0.312 \\
\hline Hours Spending & $3.62[1.374-9.549]$ & $0.009 * *$ & $1.65[0.606-4.477]$ & 0.328 \\
\hline Consultant & $0.48[0.098-2.374]$ & 0.369 & & - \\
\hline Registered Nurse & $2.18[1.016-4.686]$ & $0.045 * \bigotimes$ & $1.4[0.556-3.502]$ & 0.479 \\
\hline Medical Officer & 5.18 [0.197-1.027 ] & $0.002 *$ & $0.71[0.273-1.849]$ & 0.484 \\
\hline Resident & $0.45[1.851-1.027]$ & 0.058 & 3.2 [1.296-7.898 ] & $0.012 *$ 怄 \\
\hline \multicolumn{5}{|c|}{$\begin{array}{l}\text { *Participants who have age less than } 30 \text { years had } 3.7 \text { higher anxiety [odd ratio } 3.78[1.567-9.109], p= \\
\left.0.003^{\star}\right]\end{array}$} \\
\hline \multicolumn{5}{|c|}{ 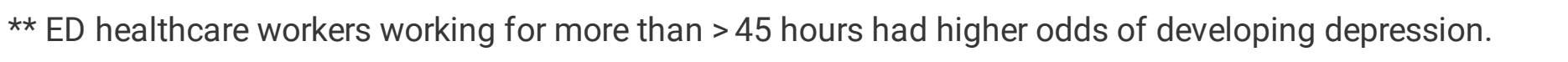 } \\
\hline \multicolumn{5}{|c|}{$\begin{array}{l}\text { * }{ }^{2} \text { nurse and medical officers had higher depression as compared to resident and consultant [Odd ratio } 2.18 \\
\left.[1.016-4.686], p=0.045^{\star}, \text { vs. } 5.18[0.197-1.027], p=0.002 *\right]\end{array}$} \\
\hline \multicolumn{5}{|c|}{$\begin{array}{l}\text { * Anxiety score was significantly higher among healthcare workers i.e., residents who were directly or } \\
\text { indirectly exposed to COVID-19 suspected or confirmed patients at work (odd ratio } 3.2 \text { [95\% C.I: } 1.296- \\
7.898 \text { ]; } p=0.012^{\star} \text { ). }\end{array}$} \\
\hline
\end{tabular}

Anxiety score was significantly higher among healthcare workers i.e., residents who were directly or indirectly exposed to COVID-19 suspected or confirmed patients at work (odd ratio 3.2 [95\% C.I: 1.296-7.898]; $p=$ $\left.0.012^{\star}\right)$. However, the odds of participants who had Working Experience and spending more hours in the emergency department were not associated with depression and anxiety. Participants who have age less than 30 years had 3.7 higher anxiety [odd ratio 3.78 [1.567-9.109], $p=0.003 *$ ], additionally, nurse and medical officers had higher depression as compared to resident and consultant [Odd ratio 2.18 [1.016-4.686], $p=$ $0.045^{*}$, vs. 5.18 [0.197-1.027], $\left.p=0.002 *\right]$ respectively.

Depression and anxiety scores among different participant's subgroups are shown in Figs. 2 and 3.

\section{Discussion}

Although there is some published literature that have looked at healthcare providers' assessment of mental health during COVID 19 pandemic, few have focused on ED physicians and nurses[8]. This is one of the first study from Pakistan focusing on mental health assessment of the emergency department healthcare providers. Our study reports a significant involvement of mental health disorders among medical officers and nurses. This is congruent with the previous research demonstrating widespread negative attitudes among healthcare providers in the emergency department[1],[8]. The involvement of medical officers and nurses seems to be directly related to the increased number of working hours. The presence of these psychological disorders 
among front line health care providers suggests that they must cope with psychological distress and are at risk of allostatic overload. The increased frequency of depression and anxiety among those who are less than 30 years age might be due to their less ED working experience and coping mechanisms that are not well developed to deal with the stress of ED. The COVID 19 pandemic has come up with an added burden to the healthcare workers of the emergency department due to added stress, insomnia, the burden of wearing personal protective equipment for long hours, fear of getting infected and subsequently putting their families at risk and patient's ignorance of not accepting that reality and seriousness of COVID 19 infection[9].

The COVID 19 has affected many frontline healthcare workers. In the low resource settings like Pakistan increases the development of psychological problems among the healthcare workers who are undoubtedly at increased risk of contracting the disease may make the situation worse. The EDs of the city are currently working at their full capacities. The increased workload together with the stressors of long duty hours may make the situation worse of delving into mental health illnesses. The lack of structured programs and training addressing this important issue is not existent. Additionally, the lack of standard operating procedures, lack of resources and prolong wearing of personal protective equipment might make the situation further gloomy. Our study findings do report an impact on the mental wellbeing of the healthcare professionals as also reported from China and Pakistan[2][5],[7],[10]. The frequency of depression and anxiety was in both nurses and physicians, but nurses were in majority. The reason could be due to their long working hours and insufficient skills for coping and resiliency.

Despite these implications stated above, the study had a few limitations. First, it included healthcare professionals from a single center and the results may not be generalizable to other settings. However, the frequency of depression and anxiety might help in the inference of the situation on other healthcare setups of the city. Second, this study was cross-sectional; thus, causal conclusions should be drawn carefully. Further studies with longitudinal designs are needed to investigate the possible causal relationships and the long-term impact of depression and anxiety on emergency department healthcare workers. Third, all data collected were self-reported by the participants, and more objective data could be used in future similar research. There is a need for an exploratory design for a comprehensive assessment of the problem. Lastly, the sample size of the study is small but its focus on the emergency department may make its utility important for formulating guidelines of prevention and coping skills for the front-liners who are involved in delivering care in the pandemic.

In conclusion, a higher percentage of mental illnesses in the emergency department healthcare workers sheds light to addresses problem with a comprehensive assessment and training program in the country. There is a need for consideration of the working hours, provision of adequate rest as well as the development of wellbeing programs aimed at empowering psychological wellbeing and resilience of the workers.

\section{References}

1. Mirza I, Jenkins R (2004) Risk factors, prevalence, and treatment of anxiety and depressive disorders in Pakistan: Systematic review. Br Med J 328:794-797

2. Sandesh R, Shahid W, Dev K, Mandhan N, Shankar P, Shaikh A, Rizwan A (2020) Impact of COVID-19 on the Mental Health of Healthcare Professionals in Pakistan. Cureus. https://doi.org/10.7759/cureus.8974 
3. Khan H, Kalia S, Itrat A, et al (2007) Prevalence and demographics of anxiety disorders: A snapshot from a community health centre in Pakistan. Ann Gen Psychiatry 6:30

4. Wong AH, Pacella-LaBarbara ML, Ray JM, Ranney ML, Chang BP (2020) Healing the Healer: Protecting Emergency Health Care Workers' Mental Health During COVID-19. Ann Emerg Med 76:379-384

5. Rana W, Mukhtar S, Mukhtar S (2020) Mental health of medical workers in Pakistan during the pandemic COVID-19 outbreak. Asian J Psychiatr 51:102080

6. Spoorthy MS (2020) Mental health problems faced by healthcare workers due to the COVID-19 pandemicA review. Asian J Psychiatr 51:102119

7. Waqas A, Aedma KK, Tariq M, Meraj H, Naveed S (2019) Validity and reliability of the Urdu version of the Hospital Anxiety \& Depression Scale for assessing antenatal anxiety and depression in Pakistan. Asian J Psychiatr 45:20-25

8. Qasim M, Awan UA, Afzal MS, Saqib MAN, Siddiqui S, Ahmed H (2020) Dataset of knowledge, attitude, practices and psychological implications of healthcare workers in Pakistan during COVID-19 pandemic. Data Br. https://doi.org/10.1016/j.dib.2020.106234

9. Tan BYQ, Chew NWS, Lee GKH, et al (2020) Psychological Impact of the COVID-19 Pandemic on Health Care Workers in Singapore. Ann Intern Med 173:317-320

10. Huang Y, Zhao N (2020) Generalized anxiety disorder, depressive symptoms and sleep quality during COVID-19 outbreak in China: a web-based cross-sectional survey. Psychiatry Res 288:112954

\section{Figures}

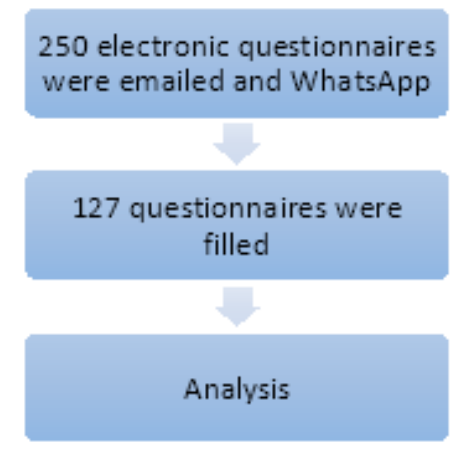

\section{Figure 1}

The study questionnaire was pre-tested and then circulated to the emergency department healthcare workers through email and WhatsApp. 


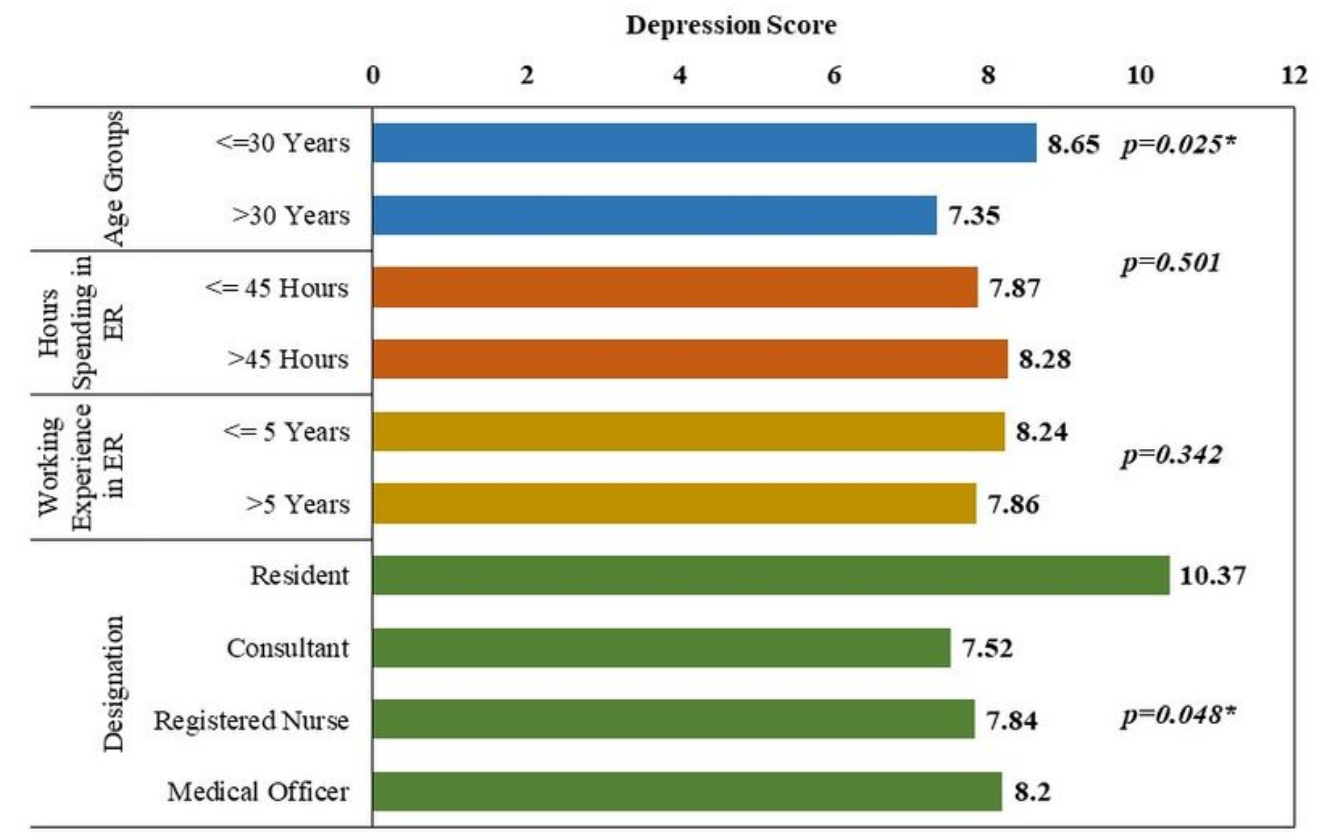

\section{Figure 2}

Bar chart showing depression scores among different groups of the study participants

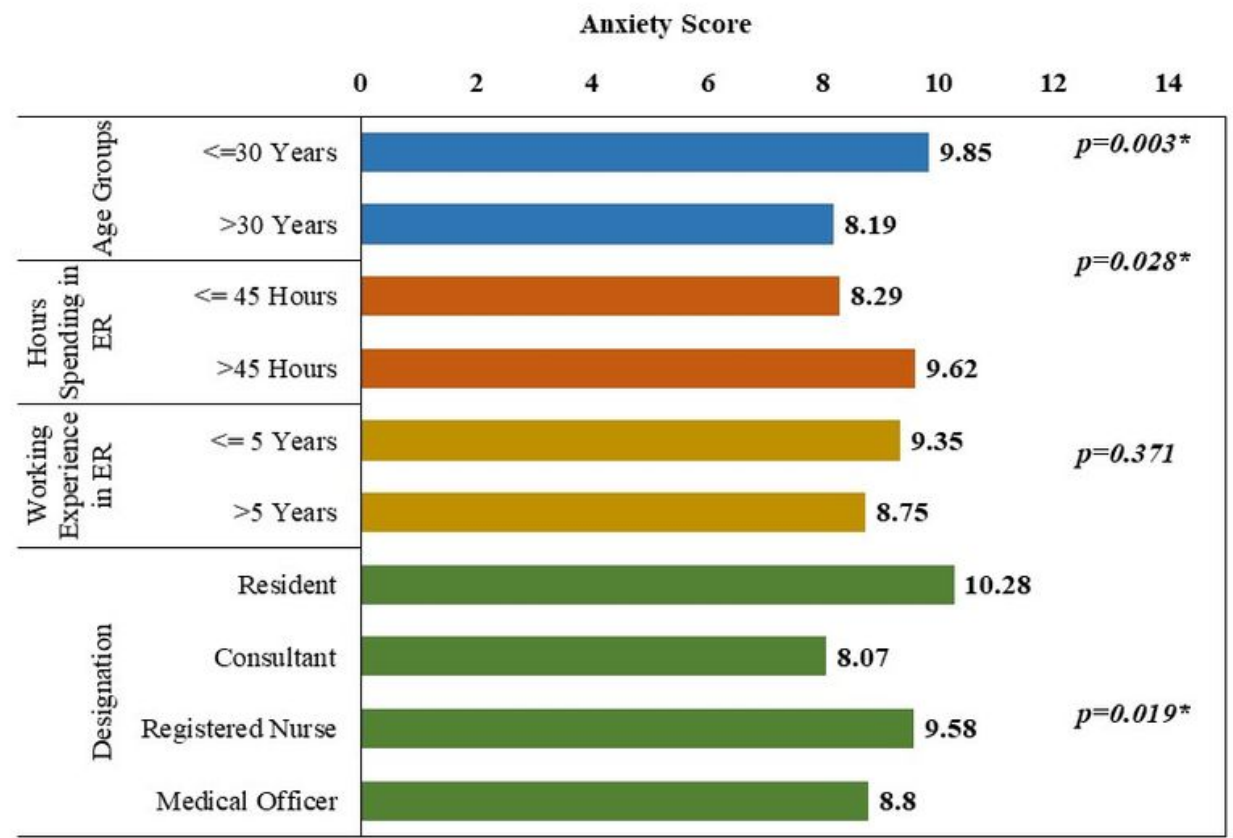

Figure 3 
Bar chart showing anxiety score among different groups of the study participants 